\title{
Bioprinting of polymer microparticles, cells and a protein at ambient conditions
}

\author{
"We have demonstrated the capability of printing \\ live cells, proteins and PLGA-PEG microparticles \\ under ambient conditions."
}

First draft submitted: 21 December 2015; Accepted for publication: 13 January 2016; Published online: 22 January 2016

\section{Keywords: 3D printing • bioprinting $\bullet$ cell viability $\bullet$ growth factor $\bullet$ microparticles $\bullet$ tissue engineering}

A number of approaches utilizing additive manufacturing techniques such as selective laser sintering, stereolithography, fused deposition modeling (FDM) and 3D printing have been employed for the production of patient-specific implants [1-5]. However, these approaches require the ceramic and polymeric materials that are used with them to be processed under conditions that are not compatible with cells and proteins. Specifically, selective laser sintering involves the fusion of particles using a laser beam at relatively high temperatures. Stereolithography requires ultraviolet light to cure photopolymerizable monomers. FDM needs high temperatures to melt the polymers, which are subsequently extruded through a nozzle. 3D printing was initially named for an additive manufacturing process in which a binder is jetted onto a powder bed to bind particles at selected positions. The binders can be harmful to live cells and denature proteins. While these harsh processing conditions cause little concern for the production of acellular scaffolds, they have prevented the incorporation of cells and therapeutic biomolecules during the fabrication process. Proteins and cells can be added postfabrication, which is, however, often associated with the inability to pattern cells and proteins in the $3 \mathrm{D}$ constructs. It is therefore important to develop production processes that are compatible with the inclusion of cells and biomolecules.
To date, bioprinting of cells and proteins has predominantly been carried out by using hydrogels, which allow printing at mild conditions. A range of hydrogels including alginate [6], gelatin methacrylate [7], gellan gum [8], poly(ethylene glycol) diacrylate [9], collagen [10] and decellularized extracellular matrix [11] have been used in bioprinting. However, hydrogel materials have a high water content, therefore have relatively low mechanical properties and are not ideal in clinical applications that require mechanical properties matching to hard tissues such as bone and articular cartilage. Stiffer materials have been used to enhance the overall mechanical properties of hydrogel composites [12]. However, the low stiffness of hydrogels may inhibit the osteogenic differentiation of both endogenous and exogenous stem cells. Therefore, biomaterials that are printable under ambient conditions and have mechanical properties matching hard tissues are needed.

We have developed a responsive microparticulate material based on a blend of poly(L-lactic-co-glycolic acid) (PLGA) and polyethylene glycol (PEG) that is printable under cell/protein compatible conditions and possesses mechanical properties superior to hydrogels [13]. When mixed with a viscous carboxymethyl cellulose (CMC) solution at room temperature, these PLGA-based microparticles form extrudable pastes that can be formed to the desired scaffold shape. We

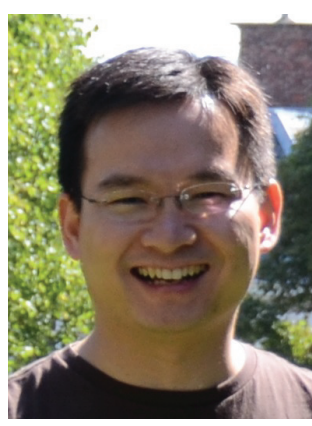

Jing Yang

'School of Pharmacy, University of Nottingham, Nottingham, NG9 5AS, UK jing.yang@nottingham.ac.uk 
used the Fab@Home bioprinting platform to fabricate constructs. In order to allow consistent extrusion without needle clogging, particles between 50 and 100 $\mu \mathrm{m}$ were printed using a tapered tip with a gauge of 16. Incubation of the scaffold at $37^{\circ} \mathrm{C}$ and in aqueous medium leads to the fusion of these microparticles and the formation of porous solid constructs.

The mechanical properties of printed constructs are comparable to those of human cancellous bone. The yield stresses and Young's modulus reached 1.22 MPa and $54.4 \mathrm{MPa}$, respectively. These values are lower than those printed using ceramic materials but under relatively harsher processing conditions.

In addition to matching the mechanical properties of bone, incorporating cells and growth factors in the scaffold can potentially accelerate healing of complex bone defects. The ability to print the PLGA-PEG material at ambient temperatures enables the patterning of cells and growth factors in scaffolds during printing.

We incorporated lysozyme-loaded PLGA-based microspheres in the PLGA-PEG material. Lysozyme was loaded into PLGA spheres by a water-in-oil-inwater double emulsion technique. A PLGA-PEGPLGA triblock copolymer was used to modify the protein release profile. Lysozyme was used as a model protein due to its similar molecular weight and isoelectric point to bone morphogenetic protein-2, which is a potent growth factor involved in bone development and repair. These protein-loaded microspheres were mixed with PLGA-PEG microparticles and CMC to form a viscous paste that was used for printing. The release of lysozyme in the printed constructs lasted for a period of at least 9 days. The majority $(\geq 61 \%)$ of released lysozyme was active.

The incorporation of live cells in the printing process is also desirable for patterning purposes. Many tissues and organs have multiple cell types that are arranged in hierarchical architectures. Cells were mixed manually into the PLGA-PEG microparticulate pastes. The viability of cells depended on the CMC carrier to particle ratio. The cell viabilities for the $1.5: 1$ ratio were 87 and $77 \%$ at day 0 and day 1 , respectively. Cell viabilities were lower for a higher ratio $(1.4: 1)$ at both time points. The viability for the $1.4: 1$ ratio dropped below $50 \%$ at day 1 . A small change in carrier:particle ratio had a significant effect on cell viability. The drop in cell viability might be attributed to the reduced lubrication resulted from a smaller amount of viscous carrier, which caused an increase of the mechanical stress on cells during extrusion though a needle.

We have demonstrated the capability of printing live cells, proteins and PLGA-PEG microparticles under ambient conditions. The resulting constructs showed mechanical properties comparable to cancellous bone. The approach has the potential for patterning biological constituents within constructs to achieve more sophisticated architectures.

\section{Financial \& competing interests disclosure}

The author has no relevant affiliations or financial involvement with any organization or entity with a financial interest in or financial conflict with the subject matter or materials discussed in the manuscript. This includes employment, consultancies, honoraria, stock ownership or options, expert testimony, grants or patents received or pending, or royalties.

No writing assistance was utilized in the production of this manuscript.

\section{Disclosure}

This Editorial is based on a Research Article published in Biofabrication titled "Cell and protein compatible 3D bioprinting of mechanically strong constructs for bone repair" the author I Yang wrote alongside co-authors MJ Sawkins, P Mistry, KM Shakesheff and LJ Bonassar.

\section{References}

1 Bose S, Vahabzadeh S, Bandyopadhyay A. Bone tissue engineering using 3D printing. Materials Today 16(12), 496-504 (2013).

2 Williams JM, Adewunmi A, Schek RM et al. Bone tissue engineering using polycaprolactone scaffolds fabricated via selective laser sintering. Biomaterials 26(23), 4817-4827 (2005).

3 Sherwood JK, Riley SL, Palazzolo R et al. A threedimensional osteochondral composite scaffold for articular cartilage repair. Biomaterials 23(24), 4739-4751 (2002).

4 Woodfield TBF, Malda J, de Wijn J, Peters F, Riesle J,

van Blitterswijk CA. Design of porous scaffolds for cartilage tissue engineering using a three-dimensional fiber-deposition technique. Biomaterials 25(18), 4149-4161 (2004).

5 Wang MO, Vorwald CE, Dreher ML et al. Evaluating 3D-printed biomaterials as scaffolds for vascularized bone tissue engineering. Adv. Materials 27(1), 138-144 (2015).

6 Hockaday LA, Kang KH, Colangelo NW et al. Rapid $3 \mathrm{D}$ printing of anatomically accurate and mechanically heterogeneous aortic valve hydrogel scaffolds. Biofabrication 4(3), 035005 (2012).

7 Kolesky DB, Truby RL, Gladman AS, Busbee TA, Homan KA, Lewis JA. 3D Bioprinting of vascularized, heterogeneous 
cell-laden tissue constructs. Adv. Materials 26(19), 3124-3130 (2014).

8 Lozano R, Stevens L, Thompson BC et al. 3D printing of layered brain-like structures using peptide modified gellan gum substrates. Biomaterials 67, 264-273 (2015).

9 Tsang VL, Chen AA, Cho LM et al. Fabrication of 3D hepatic tissues by additive photopatterning of cellular hydrogels. FASEB J. 21(3), 790-801 (2007).

10 Lee W, Lee V, Polio S et al. On-demand three-dimensional freeform fabrication of multi-layered hydrogel scaffold with fluidic channels. Biotechnol. Bioeng. 105(6), 1178-1186 (2010).
11 Pati F, Jang J, Ha D-H et al. Printing three-dimensional tissue analogues with decellularized extracellular matrix bioink. Nature Commun. 5, 3935 (2014).

12 Visser J, Melchels FP, Jeon JE et al. Reinforcement of hydrogels using three-dimensionally printed microfibres. Nature Commun. 6, 6933 (2015).

13 Sawkins MJ, Mistry P, Brown BN, Shakesheff KM, Bonassar LJ, Yang J. Cell and protein compatible 3D bioprinting of mechanically strong constructs for bone repair. Biofabrication 7(3), 035004 (2015). 
